\title{
Türk Halk Müslümanlığında Miraç Algısı
}

\author{
Mehmet Naci ÖNAL*
}

\begin{abstract}
ÖZ
Türklerin İslamiyet öncesi döneme ait inançları ile İslamiyet sonrası inançlarının harmanlanmasından oluşan halk Müslümanlığından söz edilmektedir. Halk Müslümanlığının sosyal tarihi bütün milletlerde benzer şekilde olagelir. Miraç ise, İslam dünyasının kutsal gecelerinden biri olarak kabul edilir. Miraç Kur'an'da ana hatlarıyla verilir. Tefsir, hadis ve siyerlerin yanı sıra edebiyata ve sanata yansıyan miraçla ilgili çok zengin bir külliyat mevcuttur. Miracı sadece bir rüyaya bağlayan ilahiyatçılar olduğu gibi, Peygamberin bedenen ve kısa bir zaman içinde olağanüstü bir mucize gerçekleştirdiği yönünde farklı kabulleri olan bilim insanları vardır. Burada farklı görüşler bir yana bırakılmış, Türklerin miraç içine dâhil ettikleri olağanüstülükler ele alınmıştır.

Miraç gibi muhteşem bir olay Türk Müslümanlığını derinden etkilemiştir. Eski inançlar, miraç aşamaları içine yerleştirilir. Mevlâna, Hacı Bektaş-1 Veli ve Hz. Ali gibi dini; Satuk Buğra Han gibi devletli şahsiyetler aracı kişiler olur. Bu isimlerin kültür tarihindeki saygın yerleri, miraç anlatılarına da taşınır. Bu aracı kişiler hakkında anlatılanlar çoğu zaman sorgulanmaz. İslam inancı içinde varmış gibi kabul edilir.

Hz. Muhammed miraç yolunda cenneti, cehennemi görür, yedi kat gök çıkar ve her bir gök katında bir peygamberle görüşür. En sonunda Allah'la olan buluşmaları anlatılır. Bu çıkış aşamalarının içinde hiçbir dini kaynakta yer almayan görüşmelerin yapıldığına şahit olunur. Bunlar arasında sırayla Mevlâna, Satuk Buğra Han, Hacı Bektaş-1 Veli’nin "Besmele Şerhi” adlı eseri ve Alevi kültüründeki "Kırklar Cemi”nin kutsal öyküsü sayılabilir. Biri mutasavvıf, biri hükümdar, biri Hz. Ali
\end{abstract}

Prof. Dr., Muğla Sıtkı Koçman Üniversitesi, Edebiyat Fakültesi, Türk Dili ve Edebiyatı Bölümü, Muğla/ Türkiye

E-posta: mehmetnacional@gmail.com, ORCID: 0000-0002-2397-0697,DOI: 10.32704/erdem.948901 Makale Gönderim Tarihi: 18.06.2020 * Makale Kabul Tarihi: 15.12.2020 * (Araştırma Mk.) 
olmak üzere miraçta Peygamberin gördüğü şahsiyetlerdir. "Besmele Şerhi”nde Hacı Bektaş-1 Veli, Peygamber ile yaratan arasındaki buluşmaların ve konuşmaların ayrıntılarını verir. Bu görüşmeler dini olmanın yanında mitolojik kökenlerle içi içe girmiştir.

Ruhu dünyaya inmeden önce miraçta, Peygamber Ebubekir soyundan bir gelecek olan Mevlâna’yı görür. Onun dış görünüşü ve adı ayrıntıları ile anlatılır. Dokuzuncu gök katı İslam öncesi inançları ile örtüşür. Satuk Buğra Han, atlı ve savaşçı görünümüyle miraçta boy gösterir. 330 yıl sonra dünyaya gelecek olan ruhun Türkistan diyarına İslamiyet'in yayılacağı anlamına gelir. Türklerin İslam'a yönelmelerinde ve geçişlerinde efsanevî tarihin önemli bir yeri bulunur.

Hacı Bektaş-1 Veli'nin pedagojik bir tavırla anlattığı eserinde, Peygamberin ağzından farklı renkte çıkan üç kuştan söz edilir. Kuşlar Peygamberin ağzından sırayla çıkar, büyür, denize dalar, su sıçratır; damlalarındaki nurlardan melekler yaratılır. Besmelenin önemi anlatılırken halkın anlayacağı örnek evrenden yararlanılır. Kırklar Cemi Alevi kültürünün en önemli ayin-i cem öyküsüdür. Miraçta Peygamber bir aslan görür. Bu aslana yol vermesi için firlattığ́ yüzüğü, kırklar ceminde Ali’nin parmağındadır. Sünni kültürdeki gibi, Alevi kültürünün efsanevî tarihi mitik unsurlarla bezenir.

Anahtar Kelimeler: Miraç, Halk Müslümanlığı, Mevlâna, Satuk Buğra, Besmele Şerhi, Kırklar Meclisi 


\section{The Perception of Miraj in the Turkish Folk Muslim}

\section{ABSTRACT}

It is mentioned about the folk Islam, which consists of mixing the beliefs of the Islam with the beliefs of before Islam. The social history of popular Islam is similar in all nations. Miraj is considered as one of the holy nights of the Islamic world. Ascension is given in the main lines in Qur'an. In addition to commentary, hadiths and prophetic biography, there is a rich collection of reflected in literature and art. Just as there are theologians who have linked the miraj to just one dream, there are scientists with different acknowledgments that the prophet performed an extraordinary miracle physically and in a short time. We will leave these different opinions aside. In this article, the extraordinary things that the Turks included in the miraj were discussed.

A magnificent event such as miraç deeply affected Turkish Islam. Ancient beliefs are placed within the ascension stages. Clergymen like Mevlâna, Hacı Bektaş-1 Veli ve Hz. Ali and satatesmen like Satuk Buğra Han become intermediary persons. The respected places of these names in the history of culture are also carried to the ascetic narratives. What is told about these intermediaries is often not questioned. It is considered to be within the belief of Islam.

Hz. Muhammad sees heaven and hell on the path of miraj, emerges seven skies, and talks to a prophet on each celestial floor. Finally, their meeting with God is told. It is witnessed that interviews, which are not included in any religious sources, are held within these exit stages. Among them are Mevlâna, Satuk Buğra Han, Hacı Bektaş-1 Veli’s work titled "The Basmala Commentary," and the sacred story of the forties meeting in Alevi culture. One is sufis, one is ruler, one is $\mathrm{Hz}$. $\mathrm{Ali}$, including Ali, are the figures that the Prophet saw. In "Basmala Commentary", Hacı Bektaş-1 Veli details the meetings and talks between the prophet and the creator. These interviews are intertwined with mythological origins in addition to being religious.

Before the soul descent to the world Prophet sees Rumi who the future descendant of Abu Bakr in the ascension. His appearance is explained in detail. The ninth sky floor overlaps with pre-Islamic beliefs. Satuk Buğra Han appears in the ascension with his horseman and warrior appearance. The spirit, who will be born 330 years later, will spread Islam to the land of Turkestan. The legendary history has an important place in the orientation and transition of the Turk to Islam. 
It is mentioaned about three birds that came out of the prophet's mouth with differrent colors in the work that Hacı Bektaş-1 Veli narrates with a pedagogical manner. Birds take turns out of the Prophet's mouth, grow, dive into the sea, splash water; Angels are created from the light in their drops. While explaining the importance of the Basmalah, the sample universe that the public can understand is used. Krrklar Cemi is the most important ritual story of Alevi culture. The Prophet sees a lion in Miraç. As in Sunni culture, the legendary history of Alevi culture is embellished with mythical elements.

Keywords: Miraj, Folk Islam, Mevlâna, Satuk Buğra, Basmala Commentary, forties meeting 


\section{Giriş}

Wiraç, Kur'an-1 Kerim’de İsrâ sûresi (1. ayet) ve Necm sûrelerinde (1-18 1 _ayetler) ana hatlarılla geçtiğine inanılan, "geceleyin yürümek" anlamına gelen olağanüstü bir olaydır. Bu muazzam olay hakkında ilahiyat uzmanları arasında farklı görüşler vardır. Kimileri, maddi âlemin çok ötesinde zaman ve mekân kavramlarının ortadan kalktığı, Allah'ın iradesi içinde her şeyin hüküm sürdüğü bir mucize olduğunu ileri sürerlerken (Yazır tarihsiz: 3149; Yavuz 2005: 132-135), kimileri de miracın mucize olmadığ1, sadece bir rüyadan ibaret bir olay olduğunu iddia ederler (Turan 1990: 214; Azimli 2009: 43-50). Rüyada veya gerçekte Allah'ın habibini huzuruna çağırdığına, miraç gecesi Hz. Muhammed'in feyz deryasına daldığına, bu gecenin İslam dünyasında önemli bir yeri olduğuna dair uygulamalar yaşatılmaktadır.

İslam dünyasında Kur'an'ı doğru anlamak ve açıklamak adına meal dışında çeşitli tefsirlere ve hadislere başvurulur. Tefsirlerin çeşitliliğ̈i, hadislerin farklılıkları göz önüne alındığında, miraç çalışmak kendi içinde oldukça farklı düşüncelere kapı açar. Halk muhayyilesinde geniş anlatımların içine dâhil olunması, bu yüzden mümkün olmuş olmalıdır. Kur’an mantığına uymayan akla zarar kimi olağanüstü bilgilerin halk arasında anlatılmasının amacı üzerinde ayrıca durulması gerekir. Tefsir, hadis ve siyer kaynakları birbiriyle çelişen veya örtüşmeyen bilgilere sahip olabilmektedir. Miraç yolculuğu, cennet ve cehennem tasvirleri, gök katları ve ayrıntıları, Allah'la buluşmanın geçtiği bölümlerin ayrıntıları, sanatkarlara ilham vermiş; pek çok mesnevinin konusunu teşkil etmiş (Arslan 2019: I-II), minyatür sanatç1ları ayrıntılı figürler nakşetmişlerdir (Deniz 2019. 225-283).

Bütün bu ayrıntılar içinde ilham veren ve hayal gücünü besleyen olağanüstülükler, halk dindarlığı/Müslümanlığ1 için de geçerli olmuştur. Halk dindarlığ1/Müslümanlığı ifadesi, İslam öncesi eski inançlarla İslam’a ait inançların harmanlanması anlamında kullanılmaktadır. İslam öncesi var olan benzer bilgilerin İslam'la uyumlu hale getirilmesiyle halk kendi Müslümanlığını meşrulaş̧ırır.

Konu hakkında daha önce yapılmış çalışmalar arasında, Ahmet Yaşar Ocak'ın tespit etmiş olduğu yükselme ritüelleri görülür. Elvan Çelebi’nin Menakıb-ı Kudsiyye adlı eseri başta olmak üzere çeşitli kaynaklarda, kimi şahsiyetlerin (miraç benzeri) göğe çıkış bilgilerine yer verilir. Âşık Paşa ve Muhsin Paşa gök katına çıkıp Tanrıyla görüşürler. Babaî isyanı sonrasında Baba İlyas için de benzeri bir durum söz konusudur. Tarih içinde Cengiz Han'ın hüküm- 
ranlığını müjdeleyen Teb-Tengri namıyla bilinen yaşlı adam, at üstünde göğe çıar ve Tanrıyla görüşür. Beyaz at, beyaz giysiler sonraki babaların kıyafetleri ile benzerlik arz eder (Ocak 1983: 109-111).

Bu makalede İslam tarihçileri ve İslami bilimler alanındaki bilim insanlarının tartışmaları ele alınmayacak, Tük halk kültürü içinde halk Müslümanlığının miraçla ilgili olağanüstü birikimlerine ve anlatmalarına yer verilecek; halkın kendi dini veya siyasi liderlerini yücelten birtakım olağanüstülükler üzerinde durulacaktır. Halk kültüründe, miraç olayına/mucizesine dâhil olan veya göğe yükselme aşamalarını genişletip eklemeler yapan anlatmalarla karşılaşırız. Kur'an, tefsir ve hadislerde geçen miraçla ilgili bildiklerimizin ötesinde, halk muhayyilesinde farklı anlatmalar, farklı yaklaşımlar mevcuttur. Bunlardan ilki Mevlâna, ikincisi geniş halk kitleleriyle birlikte Müslüman olan Satuk Buğra Han hakkındadır. Hacı Bektaş-1 Veli'nin yazdıkları ile Alevi-Bektaşi kültüründe geçen miraç hadiseleri de ele alınmış ve aynı bağlamda incelenmiştir. Metinlerde geçen terimler çerçevesinde terminoloji farklı ortaya çıkmış, kimi yerde Tanrı, kimi yerde Allah; kimi yerde kam veya şaman ifadeleri kullanılmiştır.

\section{Mevlâna'nın Miraçta Görülmesi}

Ahmet Eflâkî tarafindan 1353 yılında tamamlanan Âriflerin Menkıbeleri adlı eserde, Mevlâna'nın lalası Şeyh Selahaddin'in Mevlâna’yı çocukluğunda miraç zamanlarında sırtında yirmiden fazla arşa çıkardığını, yüceliğe ulaştıktan sonra kendini arşa taşıdığını ifade eder (1973: 159). Aynı eserde, Hz. Peygamber miraçta iken dikkatini cezbeden zatın kim olduğunu sorduğu, cevaben Cebrail'in Sıddık-1 Ekrem neslinden bir suret olduğunu, lakabının Celaleddin olup ahir zamanda ümmetinden olacağı, bütün milletlerden ve devlet sahiplerinden muhiplerinin ve müritlerinin olacağı ifade edilir (Ahmet Eflâkî 1973: 358-361).

Latifînnin 1546 y1lında Kanuni Sultan Süleyman'a sunduğu Latifî Tezkiresinde, Eflâkînnin miraçta Mevlâna ile ilgili verdiği bilgilerin bir benzeri yer alır: Hz. Muhammed miraca çıkarken meleklerin yaşadıkları yerleri ve gökleri dolaşır. Dokuzuncu göğün kıyısında kendisinden geçip sema eden birini görür. Nurdan sarığı güneş gibi parlar, külahının ortasında bölme çizgisi gibi bir nişanı vardır. Devreden felekler gibi sürekli dönmekte, kararsız dünya gibi devamlı cümbüş etmektedir. Semanın debdebesinden felekler dansa kalkmış, neşeli neyin sesinden felekteki melekler kendilerinden geçmiştir. 
Hz. Muhammed Cebrail'e bu zatın kim olduğunu sorar: "Peygamberlerden midir, yoksa ulu evliyalardan mıdır?" Cebrail dünyanın incisi olan Ebubekir-i Siddık'ın soyundan (onuncu atadan) geldiğini, Mevlevilerin önderi, Allah'ın yakını Celaleddin-i Rumî olduğunu ifade eder (İsen 1990: 42-43).

Mevlâna Celaleddin-i Rûmî, dinî kaynaklarında yer almayan dokuzuncu gökte oturmaktadır. Peygamberler dışında ulu bir kişinin bu katta göğün kıyısında dönerek ibadet etmekte olduğu bilgisi oldukça dikkate değerdir. Mevlâna’nın miraçta görünmesi veya gösterilmesi onun iki dünya ehli olduğunu ispat etme gayretidir. İslam dünyasında öne çıkan ve herkes tarafından sevilen bir mutasavvifin cennette görülme ihtimali "şeb-i aruz" gününde ifadesini bulan yaratanla buluşmanın sembolik görüntüsüdür. Allah’a yakın bir kul, örnek din adamı algısı, halk muhayyilesinde onun miraçtaki yerini tayin ettirir.

Bu tür bilgilerin kişiyi yüceltmek adına yapıldığ 1 veya pedagojik bağlam içinde verildiği düşünülse bile, dinleyicilerin bu tür olağanüstülüğe itiraz etmeleri pek mümkün olmaz. Üstelik kulağa hoş gelen bu öyküdür. Bazı hadislerde/ tefsirlerde göğün katlarında Peygamberlerin bazı ümmetlerinin yanlarında bulunduğu anlatılır (İmam-1 Gazâlî tarihsiz, 490-493; Yazır tarihsiz: 31413145). Yedinci katın da üzerinde dokuzuncu katta halk tarafından sevilen bir mutasavvıfın yer alması, miraç algısı içinde makul görülmüş olunmalıdır. Bu düşünce yapısı velilere tayin edilen üstünlüğün sınırının nerelere kadar ulaşabileceğini göstermektedir.

Eski Türk inanışlarındaki bazı anlatılarda dokuzuncu kat yer alır. Ancak en büyük kam bu göklere çıkabilir. Buna göre, kam ağaca yedi veya dokuz çentik atar. Her bir gök katı açılır ve sembolik manada göğe çıkar. Altıncı katta aya, yedinci katta güneşe saygısını sunar. Son kat dokuzuncu kattır. Bay Ülgen’in yüce katı buradır. Kam yerlere kapanarak kurban ettiği atın ruhunu bu katta Bay Ülgen'e sunar (Eliade 1992: 22-29; Ögel 1995, II: 163-166; Köprülü 2005: 55). Kimi anlatmalarda kam on yedi gök katına çıkar. Kam her bir gök katında bir tanrı ruhuyla karşılaşır. On altıncı katta Bay Ülgen vardır ve altın dağ üzerinde altın tahtta oturur. On yedinci en üst katta Tengere Karya Han oturur ve evreni buradan idare eder (Radloff 1986: 318-221).

Dokuzuncu ve daha üst katlar, en eski Türk inançlarında yer alır. İslam öncesi inançlar, İslam sonrasına taşınarak harmanlanır. Dokuzuncu kata hatırı sayılı ulu bilge bir kişi yerleştirilir. Böylece eski ile yeninin uyumlulaştırıldığı anlatılar, halk Müslümanlığı içinde okur-yazar olmayan sözlü kültür toplumunda karşı1ık bulur. Zamanla da yazılı ortama taşınır. 


\section{Satuk Buğra Han Destanı'nda Miraçla İlgili Bilgiler}

Hz. Muhammet miraç gecesi Burak'la göklere yükseldiğinde, göğün her bir katında önceki peygamberleri görür. Bunlar arasında tanımadığı bir zat vardır. Bunun kim olduğunu Cebrail'e sorduğunda, Cebrail bu zatın peygamber olmadığını, kendisinden üç yüz yıl sonra dünyaya inecek olan bir ruh olduğunu söyler. Türkistan'dan İslam'ı yayacak olan bu ruhun adı Abdülkerim Satuk Buğra Han'dır.

Peygamber, bu duruma çok sevinir. Dünyaya döndükten sonra, her gün dinini Türk ülkelerine yayacak olan Abdülkerim Satuk Buğra Han’a dua eder. Sahabe bu Türk hakanını merak edip gözleriyle görmek ister. Hz. Muhammed bu isteği kabul eder. Başlarında Türk başlıkları bulunan silahlı kırk atlı belirir. Bunlar Satuk Buğra Han ve arkadaşlarının ruhlarıdır (Banarlı 1987: 268).

Bazı farklılıklarıyla bir başka kaynakta bu olağanüstü olaya şöyle yer verilir. Allah resulü kanatlı Burak’a binip o gece göklere çıkar. Hiç tanımadığı bir kişiyi görür. Cebrail'e hangi peygamber olduğunu sorduğunda, Cebrail ona: "Bu bir peygamber değil, siz rıhlet ettikten üç yüz otuz üç yıl sonra fani dünyaya inecek olan Satuk Buğra Han'in ruhudur." diye cevap verir (Turan 1993: 147-187).

Satuk Buğra Han hakkında yapılan en son araştırmalarda, on bir nüsha karşılaştırılır. On bir nüshadaki ortak bilgiler miraç hadisesini biraz daha genişletir. Buna göre, Peygamber Cebrail'e bu ruhun burada yer almasının sebebini sorar. Cebrail bunu iki sebebe bağlayarak izah eder. İlki sizin dininizi ve şeriatınızı Türklere öğretecek, ikincisi bir zamanlar gelmiş olan peygamberlerden bazıları iki kişiyi bile Müslüman edemeden göçüp gittiler, oysa o çok insanı İslam'la tanı̧̧tıracak ifadesidir. Bu duruma Peygamber çok memnun olur. Elini kaldırıp dua ederek şükreder. Gönlüne Türkistan'ın sıcaklığı düştüğünü söyler. Gelecekte İslam'ın kılıcının Türkistan'a ulaşacağı için mutlu olduğunu belirtir.

Bir sonraki adımda sahabelerle görüşme aşaması genişçe anlatılır. Sahabe ile tanışması şöyledir: Hz. Muhammed sahabelerle birlikte sürekli dualar ederler. Sahabelerden Muâz b. Cebel: "Ya Resullullah hiç ara vermeden Fatiha okuyoruz, acaba bu Fatihalar kimin için okunmaktadır?” Cevaben: “Türkistan tarafına İslam kılıcı uzanmamıştı, miraçta Satuk Buğra Han'ın ruhunu gördüm. Onun ruhuna dua ediyoruz.” deyince sahabe çok sevinir. Gönül huzuru ve istekle Fatiha okumaya devam ederler. Muâz b. Cebel ayağı kalkıp: "O Satuk Buğra Han Gazi’nin temiz ruhu bize görünse tanışıp müşerref olsak, 
bizim gönlümüz de Türkistan’a meyletse nasil olur?” diye sorar. Bir saat sonra, kırk yiğit başlarında kıgız (keçe) kalpakla Türkmen atlarıyla dört yanı beyaz kalkan ve savaş silahlarını kuşanmış olarak çıkıp gelirler. Yaklaşıp Peygambere selam verirler. Yavaşça saygı ile yaklaşırlar. Resûl-i Ekrem sahabelerle tanıştırır. Bütün sahabe Satuk Buğra Han'ın ruhunu görür. Kendi aralarında şükrederler. Çok sevindik der, yine Fatiha okurlar. Daha sonra Peygamber tarafından kendilerine izin verilir. Satuk Buğra Han ve yanındaki kırk yiğidin ruhu kaybolur (Demir 2017: 22-26).

Sahabenin isteği üzerine gerçek zaman diliminde Satuk Buğra Han’ın kırk atlısıyla birlikte gözükmesi, sözlü kültür dünyasında oldukça etkileyici ve heyecan verici bir olaydır. Bu türden öykülerle göçer-evli ve savaşçı bir kültürün mensuplarının İslam'ın kılıcı olacaklarına, İslam'ı yayacaklarına işaret kabul edilir. Büyük bir ideale delalet eder. Türklere İslamiyet'i geniş ölçüde kabul ettiren bir Han için anlatılanlar, dinleyenlerin motivasyonlarını tetikleyecek türdendir. Sözlü kültür ortamı içinde, kulağa hoş gelen ve Peygamberin mucizesi içinde yer alan bir Han'ın uyruğundan olmak, Türkler için özel bir durum arz eder.

Satuk Buğra Han efsanesine benzer bir olağanüstülük Hoca Ahmet Yesevî için de anlatılır. Zamanın sınırları aşılarak Hz. Muhammed ile Yesevî arasında iletişim kurulur. Aslan Baba sahabeler arasında yer alır, aradan yaklaşık beş asır geçmiş olur, bu beş asırda Aslan Baba yaşatılır, Peygamberden aldığ 1 emanetleri Yesevîye iletir. Böylece Yesevî ile Peygamber arasındaki bağ, aracı kişiler üzerinden kurulmuş olunur.

Abdulkerim Satuk Buğra Han hakkında anlatılan olağanüstülükler, miraç olayıyla sınırlı değildir. Âdeta bir peygamber hakkında anlatılanlar, onun için de anlatılır. Bunlar arasında, doğumuna işaret olarak deprem olması, su kaynağ1 oluşması, bahçe ve çayırların yeşerip çiçeklenmesi söz konusu edilir. On iki yaşında ava çıktığında (on iki hayvanlı takvimde yer alan) tavşanın don değiştirip ulu bir kişiye dönüştüğü ve onu İslam'a davet ettiği anlatılır. Abdulkerim Satuk Buğra Han'ın kızı için de bir başka olağanüstü durum söz konusudur. "Alaca Işık" anlamına gelen Ala Nur adlı kızı, 1şık huzmesinden hamile kalır (Roux 2011: 59-60).

Satuk Buğra Han Destanı'nda, av peşindeyken tavşanın yaşlı bir insana dönüşmesi ve onu İslam'a davet etmesi, ruhunun miraçtaki görünürlüğünü destekler. Bağımsızlığına düşkün olan Türklerin güç kullanılarak İslam'ı seçmesi söz konusu değildir. İslam'dan önceki inançlarla örtüştürülen olağanüstü 
anlatılar, kendi içinde bir strateji oluşturur. Satuk Buğra Han'ın Türklerin ikili yönetim sistemindeki yeri ile Karahanlı devletinin Çin’e komşu olması göz önüne alındığında (Pritsak 1993: 253), İslam öncesi sözlü kültürün etkin olduğu dönemin şartları, mistik anlatıları, İslam'ın tercih edilmesi sürecinde halk muhayyilesi içinde uyumlulaştırılır.

\section{Hünkâr Hacı Bektaş-1 Veli'nin Besmele Şerhi Adlı Eserinde Miraçta Allah'la Peygamber Arasındaki Görüş̧meler}

Hacı Berktaş-1 Veli'nin Besmele Şerbi adlı eserinde Allah'la Peygamberin görüşmeleri ayrıntılı bir şekilde anlatılır. Bu olağanüstü görüşme dini öğreti adına, detaylarıyla verilmiş olunmalıdır. Sözlü kültür ortamını, İslam’ı anlamaya çalışan okur-yazar olmayan ahaliyi, Arapçayı ve Kur'an lafzını bilmeyen bir toplumu düşünmek gerekir. Anlatıların önemli bir kısmı onların anlayacağ 1 ve İslam öncesindeki inançlarla örtüşen türdendir. Bu görüşmelerde, öncelikle İslam'ın temel bilgilerine yer verilir: Besmelenin önemi, her bir lafzının ibadete ve sevaba delalet ettiği, daha sonra Allah ve Peygamberin aralarındaki konuşulanlar anlatılır. Buna göre, kıyamet gününe inanmayanların nasıl bir şekilde kalkacakları, amel defterlerinin sağından ve solundan verilecek olanların halleri, sırat köprüsünü kimlerin nasıl geçeceği belirtilir.

Fatiha sûresinin içinde ne varsa besmeleye yerleştirildiği bahsinden sonra, "latife" başlığı altında "sâcî" tefsirinden nakiller yapılır. Miraç gecesi yaratıllı̧la ilgili bilgiler anlatılır: Allah Peygamberine üç deniz gösterir, ilki Bahrü'l-Atâ, ikincisi Bahrü'l Cûd, üçüncüsü Bahrü'l Semâhat'dır. Resûl-i Ekrem dünyanın yetmiş katı büyüklüğündeki denizlere bakar. Allah denizlerin yanına gitmesini ister.

Denizlerin yanında besmele çektiğinde, Peygamberin ağzından yeşil bir kuş çıkar, Atâ Denizi'ne yönelir. Kuş dünya kadar büyür, denize dalar, çok su kaldırır. Arşın altına iner. Silkindiğinde kanadından bin kez su ve bu sudan bin katre nur damlar. Tanrı, damlayan her bir nurdan bir melek yaratır. Tanrı meleklere, besmele çekerek cennette köşkler yapmalarını, bahçeler, ırmaklar düzenlemelerini emreder.

Besmele çekerken “er Rahim” deyince Resûl-i Ekrem’in ağzından beyaz bir kuş çıkar, Cûd Denizi’ne varınca kuş dünya kadar büyür. Denize dalar, arşın altına iner. Kanatlarında dört yüz bin damla su ve onun nurundan melekler yaratılır. Tanrı onlara da cennette görevler verir.

Peygamber bir kez daha "er-Rahim" dediğinde ağzından mavi bir kuş çıkar. Semâhat Denizi'ne varıp dünya kadar büyür. Kuş denize dalar, arşın altına 
iner, silkinir; yetmiş bin damla su ve nurundan yetmiş bin melek yaratılır. Tanrı, onlardan kıyamete dek zikretmelerini emreder. Resûl bu iyiliklerin sadece kendisine mi ait olacağını, ümmetinin de bunlara dâhil olup olmayacağını sorduğunda, Tanrı bu rahmetin besmele çeken herkese ait olacağını söyler.

Resûl geri dönerken cennete bakmaz, Allah bakmasını emreder. İlk cennet Firdevs Cenneti'dir ve içinden dört irmak geçer. Biri bal, biri süt, biri su biri de tertemiz içecektir. Kubbeyi dolaşır, kilidinin besmele olduğunu öğrenir. Kubbeden geçerken nurdan yapılmış besmele görür; besmele (بسم الله ارحمن ارحيم)'nin (ilk) "mim"inde Allah'1, "he"sinde er-rahim'i, (son) "mim"inde akmakta olan birer ırmak gördüğünü ifade eder. Allah, ümmetinden besmele çekenlerin bu ırmaklardan kana kana içecekleri buyurur.

Besmele Şerbinnde üç kuş meselesi de oldukça dikkate değerdir. Bu kuşlar Peygamberin ağzından çıkarlar. Büyür, denize dalar, sudan damlayan nurlardan melekler yaratılır. Bir yaratılış mitolojisiyle karşılaşırız. Kur'an'da böyle bir bilgiden hiç söz edilmez.

Türk mitolojisinde, ölen yiğitlerin ruhları doğan (kuşu) olup göklere uçar. Sembolik olarak cennete gider. Orhun yazıtlarında ölenler için, ölmek ifadesi kullanılmaz; “uçu birdi, “uçup gitti," “uçarak vardı,” şeklinde geçer (Ögel 1995, II: 129). Peygamberin ağzından çıkan kuş bizleri eski halk inançlarına götürür. Bir kişinin ölümüne "can kafesten uçar" denir. Can kuşunun ağızdan veya burundan çıktığına kuşa dönüştüğüne inanılır. "Canım burnumda" deyimi, bizlere derin kültür kodlarını hatırlatır. Cennete giden insan ruhu için "cennet kuşu” ifadesi kullanılır. İnsanın canı / ruhu kuşa dönüşür. Türk mitolojisinde on yedinci kat, evrenin en üst katıdır. Ölen kişinin ruhu "uçmak"a yani cennete yükselir. Yunus Emre'nin şïrlerinde de cennet “uçmak" şeklinde yer alır.

Müslüman şehitlerin ruhları yeşil kuşun kılavuzluğunda cennete ulaşacağına inanılır. Gökteki cennet "Süt Ak Göl," “Ak” kavramları ile karşılanır (Akalın 1993: 137-139; Bayat 2007: 59). İslam öncesi Türk inançlarında Beltirler arasında renklerle ilgili uygulamalar göze çarpar. "Üldürbe" denen bir tören nesnesi hazırlanır. Üldürbe için bir kartal avlanmalıdır. Beyaz ve mavi kumaş paçaları ile şapkanın etrafı çerçevelenir. Öldürülen kartalın tüyleri bu kumaş parçaları arasına yerleştirilir. İnanışa göre kartalı bizzat ruhlar gönderir. Yeşil kayın ağacının dalları, bu törenlerde kullanılır (İnan 1998: 218).

Peygamberin ağzından çıkan üç kuş, ölenlerin ruhunun ağzından çıkan cana benzer. Peygamberin canından ayrılan ruh ile yaratılışın öyküsü anlatılır. 
Onun bedeninden ayrılan ama ölmeyen, onun ruhunun / varlığının yüzü hürmetine yaratılan kâinatın sembolik bir anlatımı Hünkar Hacı Bektaş-1 Veli tarafindan öğretiyle biçimlendirilmiştir. Peygamberin ağzından çıkan kuş onun ruhunu temsil eder. Kuş büyür dünya kadar olur. Denize dalar, aşağ1 dünyaya inişin bir semboldür. Yukarı çıkınca damlaların sayıları ve oluşan nurlardan meleklerin yaratılması, Habibi ile Yaratan'ın buluşması, insanların anlayacağı şekilde somutlaştırılır.

Hz. Muhammed'in siyah kumaştan olan ünlü sancağının adı “Ukab”dır. Ukab Türklerde kartal, şahin, atmaca, tavşancıl ve benzeri kuş manasındadır (Akalın 1993: 148). En eski inançlar arasında yer alan "umay" mavi ve beyaz bir kuş kılığına girer. Yaratıcı ruhla bağları vardır. Um kökünden gelir. Tunguzlarda Omay /Umay, omo / umu kökünde yumurta birakma manasında kullanılır (Karakurt 2011: 220). Yeşil, beyaz ve mavi kuşlar bir sembol niteliğindedir. Yeşil “yeryüzüne," beyaz "su yüzüne," mavi "gökyüzüne” yani üç evrene işaret eder. "Besmele Şerhi”nde evrenin nasıl yaratılmış olduğu "Habibinin yüzü hürmetine" bağlanması sembolik olarak işlenir.

Muhammed'in “mim”i Hz. Muhammed'in makamının sembolüdür. İnanışa göre, Tanrı kendini kâmil insanın gözünden kudretini seyreder (Muslihiddin Vahŷ̂, 2001: 35). Kư'ân-1 Kerim'de geçen kimi sembolik harflerin anlamları üzerinde çeşitli çalışmalar yapılmı̧sır. "mim" ve "he" harflerinin sembolik pek çok anlamlar taşıdığı öngörülür. "mim” harfinin ses ve söylem bakımından yumuşaklığı, letafeti çağrıştırır ve anne şefkatine dek götürülür. "he" harfi ise eğilmiş insan figürüne benzetilir: yüceltmek, himmet etmek, lebbeyk/emrindeyim anlamalarına gelir (Namlı 2015: 85-86; 95-96).

Miraç'ta Tanrı ile Peygamber arasındaki konuşmalar devam eder. Besmelenin önemini öne çıkaran ifadeler yer alır. Allah: "İnsanlar beni evlerine davet etsinler." dediğinde, Resûl: "İnsanlar seni nasıl ağırlasınlar?” diye sorar. Tanr1: "Ey benim Habibim, müminlere söyle, gönül evlerini temizlesinler, hırsı, cimriliği, düşmanlığı, hainliği ve kıskançlığın çerini çöpünü çıkarsınlar. Kötü işlerden pişman olsun, muhabbet sefasını döşesinler, tevekkül ve sabır içinde olsunlar." der. Kelime-i şahadet getirip "Lâilahe illallah Muhammeden Resullullah" derken önce benim sonra senin adını söylerler, her ibadette önce benim farzımı, sonra senin sünnetini yaparlar. Senin ümmetine sen şefaat edersen, ben de lütufta bulunurum. Devamında Allah, besmele çekenlere yakın olacağını, ayıplarını örteceğini, rahmetiyle ahirette diğerlerinin yanında mahcup etmeyeceğini, işledikleri günahları sevaplara dönüştüreceğini, iyilikle değiştireceğini ifade eder. 
Allah ve Resûlü konuşmalarında, Allah, ümmetinin yıldızlar, ay ve güneş gibi ibadet etmelerini buyurur. Peygamber, ne demek istediğini sorduğunda, y1ldızların akşam doğduğunu, ertesi güne kadar (müminlerin) ibadette olmalarını, olmazsa gecenin bir bölümünde bunu yapmayanlar gün(eş) ve gece (arasında) ibadet etmelerini ister (Hünkâr Hacı Bektaş-1 Veli, 2007: 42-90; 92-133). Bu bilgiler ışı̆̆ında namaz vakitleri ayrıntıları ile ele alınmış olunur.

Hünkâr Hacı Bektaş-1 Veli'nin eserinde yazılanlar, hem İslam kurallarını içerir hem de birtakım olağanüstülükleri gözler önüne serer. Miracın kendisi olağanüstüdür, lakin Allah'la Resulünün görüşmelerinin ayrıntıları da olağanüstülüklerle doludur. Bunların bir kısmı İslam öncesi inançlarla pekişir. Kuş donuna girmek en eski Türk inançlarını içinde barındırır. Kuşa dönüşümleri destekleyen bir bilgiyi de İmam-1 Gazali'den öğreniriz. İnsanların ruhlarının bir kuşun kanadında cennete uçacağına dair bilgilerden söz eder. Kabirle ilgili ayrıntıları anlatırken kimilerinin iki veya üç ay kabirlerinde kaldıktan sonra, ruhlarının bir cennet kuşunun üzerine bineceklerini ve böylece cennete kadar uçacaklarını ifade eder. Gazali, bu bilgiyi sahih bir hadise dayandırır: Müminin ruhu kuş ile beraberdir. Cennet ağaçlarından birine asılmış durur, der (İmam-1 Gazali 1993: 25).

Hacı Bektaş-1 Veli'nin eserinde geçen bilgilerin bazıları, pedagojik olarak anlaşılabilir. Sırat köprüsü hakkındaki ayrıntıda: "Her mümin önündeki sırat köprüsü arşa kadar dikilidir, nur yaratayım ki, onun aydınlığında yüz bin asi beraber geçsin,” şeklinde anlatılır (Hünkâr Hacı Bektaş-1 Veli 2007: 141). Gazali'de onu destekleyen ifadeler yer alır. İbn Mesûd'un rivayetine dayandırılan "Sırat Köprüsü" cehennem üzerinde kıldan ince kılıçtan keskin bir köprü olarak verilir. Allah'ın emrini tutanların yıldırım gibi geçecekleri, kâfir ve isyancıların ise ayaklarının kanlar içinde kalacakları ve cehenneme düşecekleri anlatılır (Gazali tarihsiz: 545).

Kurban bayramlarında büyükler çocuklara, kesilen kurbanın üzerine binerek onları sırat köprüsünden salimen çarçabuk cehennem ateşinin üzerinden geçireceğini anlatırlar. Sırat köprüsü İslam öncesi en eski inançları içinde barındırır. Zerdüşt inancında sırat köprüsü ayrıntılarıyla verilir. Daena, Çînvâd köprüsü, ruhların iyilik ve kötülüklerinin tartıldığı bir yoldur. Metafizik yolculukta "kıldan ince kıllçtan keskincedir." Zerdüşt Ardâvîrâf, fizikötesi evren yolculuğunda Çînvâd Köprüsünden geçer. Mazdeist inanışa göre, bütün ölülerin ruhları bu köprüden geçer. İyiler için $27 \mathrm{~m}$ genişliğinde, kötüler için "kıldan ince kılıçtan keskincedir." Dev günahkârları cehenneme firlatır (Ardâvîrâf 2011: 18, 30-34, 54). Zerdüşt kültürü etkisinden Şiâ dünyasina taşınan bilgiler içinde, Hz. Ali'ye mal edilen sırat köprüsünden geçiş yer alır. 
Burada Çînvâd köprüsü yerine Jızat ve Keramet-i İmam Ali yer alır (Ünlüsoy 2014: 358-382).

Sırat yolculuğuna benzer bilgiler gök Tanrı inanışında da vardır. Kam yer altı tamu (cehennem) yolculuğunda kıldan ince köprüden geçmek zorundadır (İnan 1995: 107; Bayat 2019: 47).

\section{Miraç ve Kurklar Cemi}

Alevi-Bektaşi kültüründe miraç özel bir konuma sahiptir. Alevi-Bektaşi kültürünün emirlerini içeren "Buyruk" larda "Kırklar Cemi” ile miraç ilişkisi anlatılır. Rivayete göre, Muhammet miraca çıktığında yolda bir aslan görür. Bir ses: "Aslan senden bir nişan ister, yüzüğünü ver," der. Çıkarıp hatemi ağzına verir. Böylece bir nişan olur. İçinden "Amcaoğlu Ali burada olsaydı bu aslanın hakkından gelirdi” diye geçirir. Yedinci kata ulaşır. Allah'la buluşur. Hakk'ın yüzünü görür, sessiz ve sözsüz olarak doksan bin sır söyleşirler. Doksan bin kelamından gayri otuz bini de şeriatla ilgilidir. Toplamı yüz yirmi dört bin kelam konuşulur. Bunlardan altmış bini Ali'de sırrolur.

Muhammed miraçtan dönerken Mina’da bir kubbe görür. Kırkların sohbette cem oldukları eve uğrar. İzin vermezler, birkaç kez gaipten uyarılar alınca: "Yoksulların hizmetçisiyim." dediğinde kapı açılır. Kapıyı açıp içeri varır. Bir başka anlatımda, ilk girişte Kırklardan biri: "Kimdir" diye sorar. Gaipten gelen ses: "Muhammed Nebi geldi" şeklindedir. İçeri girer, kendisine yer gösterilir. Ondan sonra Cebrail gelir, hatemi (mühürlü yüzüğü) çıkarıp önüne koyar. $\mathrm{O}$ zaman Kırklar ayağa kalkarlar. Peygamber yerine oturur. Muhammed sizler kimlersiniz, diye sorar: "Biz kırklarız bir gönül, bir cihetiz, derler. Birimiz ne ise, varımız odur." Kırkların hangisinin büyük hangisinin küçük olduğu anlaşılmaz. Bunu üzerine: "Sizin küçüğünüz kimdir, ulunuz kimdir?” diye sorar. Bu soruya hep birlikte cevap verirler. Kırklar birdir, birimiz kırktır, derler. "Sizin biriniz ne oldu?" diye sorunca Kurklar: "Seyyidullah gitti." derler. Sonra da "Ya Muhammed ne çok sordun." derler. Salmani'yi Hızır bil derler. O zaman Peygamber Kırklardan nişan ister. Kırklardan biri kolunu kaldırır, Muhammed neşter vurur. Kırkların her birinden aynı anda birer damla kan akar.

Salman Fars'tan gelir. Bir tane üzüm getirir. Bazı Alevi rivayetlerinde Miraç’ta Hz. Muhammed'e süt, bal ve elma verildiğine inanılır. Bal aşka, süt sevgiye, elma dostluğa işarettir. Muhammed bu üzümü ezip şerbet eyler. Kırklar içip coşarlar. Ayağa kalkıp sema dönmeye hu hu demeye başlarlar. Muhammed semaya girer. Sarı̆̆ı başından düşünce kırk pare olur, bunu da Kırklar kuşanırlar. Ali ötekilerden daha taşkın bir vaziyette cezbe içinde ortaya atılır. $\mathrm{Bu}$ sırada ağzından Hz. Muhammed'in (miraçta iken) aslana atmı̧ olduğu 
mühürlü yüzüğü çıkarır. Muhammed o zaman Ali'yi tanır ve onun gerçekliğini anlar. Hakk'ın anlaşılması için âyin-i cem gelenek olur. Diğer anlatımda, Pirlerinin Şah-1 Merdan Ali olduğunu söylerler. Meclise Ali gelir, saygiyla karşılanır. Elindeki nişanı, mührü görürler. Sahabe Muhammed'e Allah'ın ne buyurduğunu beyan etmesini ister. Dil ile ikrar, kalp ile tasdik edip iman ve emek gerektiğini söyler. Özünü, ehlini ve dilini yâr eylemelerini belirtir. Hakikat nedir diye sorduklarında: "Hakikat Şah-1 Merdan Ali hakkında geldiğini, varın ona iradet getirin.” der.

Buyruklar üzerinde çalı̧san S. Aytekin Maraş Nüshasındaki "Kırklar Cemi”nde de benzer bilgiler olduğunu yazar. Maraş Nüshasındaki küçük farklar şöyledir. Kırklar meclisinin kapısını ilk çaldığında, kendini Peygamber olarak tanıtır. Kapı açılmaz. İkincisinde de aynı şey olur. Üçüncüsünde kendini "fakir" olarak ifade eder ve kapı açılır. İçeriye girdiğinde kırkları görür. Bunlardan yirmi ikisi kadın, on yedisi erkektir. Kolları kesildiğinde otuz dokuzunun kolundan kan damladığı, kırkıncının pencereden içeri kan damladığı görülür. Bu yazmanın sonunda $\mathrm{Hz}$. Muhammed ve $\mathrm{Hz}$. Ali birbirleriyle musahip olurlar (Aytekin 1958: 7-9; 155-161; Gökbel 2019: 595-596).

Alevi kültüründe miraç tazelenme, arınma ve nefsin ölümüdür. Tarikat yoluyla yeniden doğuş anlamına gelir. Anasız babasız doğuş olarak dünyaya ikinci kez gelişin simgesidir. Miraç yenilenme, evrenle ve doğayla kucaklaşma, Tanrı ile bir olma, gizlerin özüne inme demektir. Alevi kültüründe "Miraç kutlama" sözü oldukça yaygındır. İlk anlamı ikrar verme, nasip alıp tören bittikten sonra söylenen tebrik; ikinci anlamı görgüden geçerek ikrar tazeleyen ruhsal açıdan temizlenen talibe tören sonrası kutlama ifadesidir: "Miracin kutlu olsun!"

Alevi-Bektaşi kültüründe "miraç görmek" (erkân görmek) uyarıcı (mürşit) katına varıp erkân ile meydan görerek Bektaşi olmaya verilen addır. Bektaşilerde isteklinin nasip almasına miraç denir. Miraçlama, ayin-i cem törenlerinde $\mathrm{Hz}$. Muhammed'in miraca gidişi sırasında yolda rastladığı aslana yüzüğünü vererek yoluna devam etmesi, Allah ile görüşmesi, miraçtan sonra, kırklar meclisine katılması, üzümü ezip kırklara pay etmesi ve sonunda onlarla birlikte semah etmesi inancını anlatan şiirlere verilen addır (Artun 2014: 360).

Hz. Ali’nin bir aslan şeklinde/donunda miraçta görünmesi, olağanüstülükler içine bir olağanüstülük daha yerleştirmek demektir. Mucize içinde bir mucize söz konusudur. Ali'nin aslan sıfatını almasının olağanüstü öyküsü anlatılır, bu vesileyle Alevi kültürü içindeki büyüklüğüne delil oluşturulur. Ali, bütün savaşlarda aslan gibi savaşmış, pek çoğunda komutanlık yapmıştır. Miraç içinde aslan karşısına çıktı̆̆ında içinden Peygamberin: “Ali yanımda olsaydı.” ifadesi 
ona olan güveninin ve zor zamanlarda yanında olduğunun ima edilmesidir.

Evliya ve erenlerden kırk kişinin ermiş olduğuna, içlerinde Hz. Muhammed, Hz. Ali, Fatıma, Salman-i Farisi'nin bulunduğuna, kırkların gizli güçleri olduğuna inanılır, kutsallıklarına saygı gösterilir. Miraçta Ali'nin aslana dönüşümü, don değiştirme yeteneği, mitolojik bir derinliğe işaret eder. Burada kam ile bağlar kurulur, İslam öncesi din adamlarının bu olağanüstülükleri İslam sonrasına taşınır. Kamlar da her türlü canlı varlığın kılığına dönüşebilir. Hz. Ali'nin miraçta aslan suretinde yer alması, reenkarnasyon inanışının bir başka boyutudur (Roux 2011: 59-60).

Muhammet ve Ali'nin musahip olmaları, Ali'nin diğer olağanüstülükler göstermesi, Allah-Muhammed-Ali üçlemesi, Ali sevgisinin ne denli ileri boyutlara taşındığının göstergesidir. Seyyid Hüseyin, Fuzuli gibi Alevi Bektaşi şairler yanında, Yazıcıŏ̆lu Mehmet ve Şemseddin Sivasî gibi Sünni isimler de Ali'nin mucizeleri hakkında benzer bilgilere eserlerinde yer verirler (Ünlüsoy 2014: 358-382). Ali hakkında anlatılan efsaneler, Alevi sözlü kültürü içinde devam ettirilir (Önal 2003: 343-366; 2013: 343-366). Hz. Ali cenkleri Türk halk edebiyatında büyük bir külliyat oluşturur (Çetin 1997; Demir ve $104 \quad$ Erdem 2007).

Miraç sonrası olanlar, Alevi kültüründeki sistematiği verir. Kadın erkek denktir. Birimiz hepimiz, hepimiz birimiz içindir. Anlatılanlar, kesrette vahdet, vahdetteki inancın açığa çıkarılması, Kırklar (Ashab-1 Suffa)'ın pirinin Ali olması, onun şah-1 velayet (velilerin şahı) sıfatını kazanması anlamında gelir (Gökbel 2019: 498-500).

Meşhur kırklar meclisi veya kırklar içinde, tevazua, bir olmaya ve eşit olmaya işaret edilir. Muhammed'in Peygamberliğini değil, insan olma yönünü öne çıkarılır, Peygamberlik imtihanından geçirilir. Bir üzüm tanesinin kırklar arasında nasıl pay edileceği akıl yoluyla sınanır. Aralarında büyük küçük yoktur, denk bir durum söz konusudur. Bu durum Peygamberin dahi içinde bulunduğu bir eşitlik anlamına gelir. Peygamberliğin manası akıl ve birliğge taşınır. Bu taşınma olağanüstülükleri de içine alacak şekilde biçimlendirilir. Bir kan damlasının herkesten aynı anda akması bunun işaretidir.

Alevi sözlü kültürü, Hz. Ali’yi ulular. Bu yapılırken Hz. Muhammed'le kimi zaman eşitleme veya denkleştirme yoluna gidilir; buna rağmen Ali'nin üçleme içindeki yeri son sıradır: Allah-Muhammed-Ali. Büyük Alevi ozanlar bu üçlemeye dikkat ederlerse de, yine de merkezde Ali yer alır. Şiirlerin konuları Ali etrafında yoğunlaşır. Düvaz İmam şiirleri Ali soyu üzerinden yürütülür. 


\section{SONUÇ}

Türk Müslümanlığı bağlamında İslam öncesi eski inançlardan İslam'a geçişte en çok etkilenilen muazzam olay şüphesiz miraçtır. Kamların adanan kurbanın ruhunu, gök katına çıkarmak için yaptıkları ayinler bilinir. Yükselme ritüelleri dünyanın pek çok inanışında yer alır. İlahiyat araştırmacıları arasında miraç tam manasıyla bir "mesele" teşkil etmektedir. Birbirleriyle farklı bakış açıları ortak paydalardan çoktur. Ortak paydalar sadece Kur'an-1 Kerim'de geçen bilgilerle sınırlıdır. Hadis, tefsir, hilye, siyer kaynaklarına, oradan edebiyata ve sanata, ardından halk inançlarına taşınan kocaman külliyat/lar birbiriyle az örtüşür haldedir.

Okuryazar olmayan halkın pek çoğu konar-göçer olan ve Arapça bilmeyen, geçmiş zamanın yaşam koşulları içinde, bilgi edinmenin zor olduğu çağlarda duymaya yönelik dini algılamalar söz konusudur. Burada aracı kişiler önemli bir yer tutar. Eski kamların yerini alan babalar/veliler/pîrler/şeyhler üzerinden dini bilgiler öğrenilir. Algıların sırrı, halkın eski bildikleri ile yeni öğrendikleri arasında uyumlulaştırma gayreti içinde aranmalıdır. Ulu şahsiyetler hakkında anlatılan efsaneler/menkıbeler bu duruma örnek oluşturur. Eski ve yeni inançlar arasındaki gidiş-gelişlerle kişiler yüceltirken uyumlulaştırılmış dini bir bellek -oluşturulur.

Mevlâna ulu bir yere, miraca yerleştirilir. Abdülkerim Satuk Buğra Han ve ahalisiyle Müslüman olurken hakkında miraç dâhil olmak üzere anlatılan olağanüstü pek çok efsane vardır. Bu efsanelere dayalı gelenek, inanç algılarını biçimlendirmiştir. Kolektif toplum ve düşünce yapısını da dikkate almak, efsanevî düşünme biçimiyle birlikte inanç tarihinin gerçekliği kavramak gerekir. Bir yanıyla İslam öncesi inanç kodları İslam sonrası ile uyumlu hale getirilirken öte yanıyla yönetici/ler efsanelerle adeta kutsal bir kişiye dönüştürülür. Abdulkerim Satuk Buğra Han için anlatılan efsaneler/kerametler/ mucizeler, İslam öncesi inançlarla örtüştürülerek Türklerin İslamlaşması süreci kolaylaştırılmıştır.

Hacı Bektaş-1 Veli'nin Besmele Şerbi adlı eseri hem dini hem de mitolojik bir uyumlulaştırmadan oluşan pedagojik bir eserdir. Diğer sûfiler gibi o da halka anlayacakları hâl ile olağanüstülükle bezenmiş kâle/lisana döker. Peygamber aracılığıyla insanlara gönderilen kitabın sınırlarını aşan, peygamberlerin ardılları ermiş kişileri öne çıkaran ve bilinenin dışına düşen "sözlü İslam tarihiyle” karşı karşıya kalırız. Alevi-Bektaşi-Sünni halk dindarlığı/Müslümanlığ 1 içinde, fark etmeksizin İslam öncesi birtakım mitler/efsaneler/halk inanışları İslam'a taşınmıştır. 
İslam öncesi mit, efsane/menkıbe, halk inançlarının hepsi inanç kodludur ve halk Müslümanlığını içinde olabildiğince harmanlanmıştır. Bu geçişler ve algıların nasıl ve hangi ortamlarda gerçekleştirildiği meselesi, ilahiyatçılar kadar, halk kültürü ile iştigal edenlerin görevleri arasındadır. Bu değişim ve dönüşümlerin nerelerden nerelere intikal ettiği ve algılandığı meselesi, gelecekte de pek çok araştırmaya açık bir mevzudur. 


\section{KAYNAKLAR}

Ahmet Eflâkî, Âriflerin Menkıbeleri (Menakıb al- Ârifin) I, (çev. Tahsin Yazıc1), İstanbul: Hürriyet Yayınları.

Akalın, L. Sami (1993). Türk Folklorunda Kuşlar, Ankara: Kültür Bakanllğ1 Yayınları.

Ardâvîrâf, (2011). Ardâvîrâfnâme (Cennet, Araf ve Cehennem), (çev. Nimet Yıldırım), Ankara: Pinhan Yayınları.

Arslan, Mehmet (2019), Manzum Mirâc-nâme ve Mirâciyyeler, Sivas: Sivas Cumhuriyet Üniversitesi Yay. 2 Cilt.

Artun, Erman (2014). Ansiklopedik Halkbilim / Halk Edebiyatı Sözlüğ̈̈ Tanımlar-Motifler-kavramlar, Adana: Karahan Yayınları.

Aytekin, Sefer (1958). Buyruk, Ankara: Emek Basım Yayınevi.

Azimli, Mehmet (2009), "İsra ve Miraç Olayları Üzerine Bazı Mülahazalar," Bilimname, XVI, s. 43-58.

Banarlı, Nihad Sâmi (1987). Resimli Türk Edebiyâtı Târibi, Destanlar Devrinden Zamanımıza Kadar, İstanbul: MEB Yayınları.

Bayat, Fuzuli (2007). Türk Mitolojik Sistemi Kartal Dişi, Mitolojik Ana, Umay Paradigmasinda İlkel Mitolojik Kategoriler, İyeler, Demonoloji 2, İstanbul: Ötüken Yayınları.

Bayat, Fuzuli, (2019). Türk Şaman Metinleri Efsaneler ve Memoratlar, 3. bs., İstanbul: Ötüken Yayınları.

Çetin, İsmet (1997), Türk Edebiyatında Hz. Ali Cenknâmeleri, Ankara: Kültür Bakanlığı Yayınları.

Deniz, A. Çağlar (2019), "Mucizelerin İkonografisi: Miraç ve Miraçnameler,” Alevilik-Bektaşilik Araștırmaları Dergisi, S.19, s.225-283.

Demir, Necati ve Mehmet Dursun Erdem, (2007). Hazret-i Ali Destan, Ankara: Destan Yayınları, 2 cilt.

Demir, Necati (2017). Satuk Buğra Han Destanı, 3. bs., İstanbul: Ötüken Yayınları.

Eliade, Mircea (1992). İmgeler ve Simgeler, (çev. Mehmet Ali Kılıçbay), Ankara: Gece Yayınları. 
Gökbel, Ahmet (2019). Ansiklopedik Alevi Bektaşi Terimleri Sözlüğü, Ankara: AKM Yayınları.

Hünkâr Hacı Bektâş-1 Velî (2007). Besmele Şerbi (Şerb-i Besmele), (hzl. Hamide Duran), Ankara: Türkiye Diyanet Vakfı Yayınları.

İmâm-1 Gazâlî (1993). Kur'ân-1 Kerîmde Kıyamet ve Âhiret, 11. bs., (çev. Ömer Beğ), İstanbul: Hakikat Yayınları.

İmam-1 Gazâlî (tarihsiz). Allah Nizamında Kalplerin Keş̧i (çev. Atilla Cengizoğlu), İstanbul: Merve Yayınları.

Inan, Abdulkadir (1995). Taribte ve Günümüzde Şamanizm Materyeller ve Incelemeler, Ankara: Türk Tarih Kurumu Yayınları.

İnan, Abdulkadir (1998). "Beltir Türklerinde Göktanrıya Kurban Töreni,” Makaleler ve Incelemler, 2. bs., Ankara: Türk Tarih Kurumu Yayınları. Ankara, s.215-221.

İsen, Mustafa (1990). Latîî Tezkiresi, Ankara: Kültür Bakanlığı Yayınları.

Karakurt, Deniz (2011). Açıklamalı Ansiklopedik Mitoloji Sözlüğü, e-kitap.

Köprülü, M. Fuad (2005). Türk Tarib-i Dinîsi, Ankara: Akçağ Yayınları.

Muslihiddin Vahyî (2001). Miraçül-Beyân Miracın Tasavvufi Boyutu, (hzl. Mustafa Tatçı-Cemâl Kurnaz), Ankara: Bizim Büro Yayınları.

Namlı, Tuncer (2015), "Dil ve Vahiy Tarihine Işık Tutan Çarpıcı Sûre Başlıkları: Mukattaa Harfleri,” Eskiyeni, Sayı: 30/Bahar, s.85-131.

Ocak, Ahmet Yaşar (1983). Bektaşî Menâkıbnâmelerinde İslam Öncesi İnanç Motifleri, İstanbul: Enderun Yayınlar1.

Ocak, Ahmet Yaşar (1992). Kültür Taribi Kaynăğ Olarak Menâkıbnâmeler (Metodolojik Bir Yaklaşım), Ankara: Türk Tarih Kurumu Yayınları.

Ögel, Bahaeddin (1995). Türk Mitolojisi Kaynaklar ve Açılamaları ile Destanlar, Ankara: Türk Tarih Kurumu Yayınları, 2. Cilt.

Önal, Mehmet Naci (2003). Muğla Efsaneleri (Araştırma-İnceleme), Muğla: Muğla Üniversitesi Yayınları.

Önal, Mehmet Naci (2013). “Muğla'da Alevi-Tahtacı Kültürü,” Turkish Studies, S. 8/9, s. 343-366.

Pritsak, Omelyan (1993). “Karahanlılar,”İslam Ansiklopedisi, İstanbul: MEB Yayınları, 6. Cilt, s. 251-273. 
Radloff, W. (1986). Sibirya'dan Seçmeler, (çev. Ahmet Temir), Ankara: Kültür ve Turizm Bakanlı̆̆g Yayınları.

Roux, Jean Poul (2011). Eski Türk Mitolojisi, (çev. Musa Yaşar Sağlam), Ankara: Bilgesu Yayınları.

Turan, Osman (1990). Türk Cihan Hakimiyeti Mefkuresi Taribi, İstanbul: Nakışlar Yayınları.

Turan, Osman (1993). "Satuk Buğra Han Menkıbesi ve Tarih," Selçuklular ve İslamiyet, İstanbul: Boğaziçi Yayınları, s.147-187.

Ünlüsoy, Kamile (2014). "Şî̂ Kültüründeki Mucizeler Üzerine Bir Değerlendirme: Abbas Azîzînnin "320 Dasıtan Az Mu 'Jizat ve Kerâmât-1 İmam Ali (A.S.) Eseri Örneğinde," Uluslararası Sosyal Araştırmalar Dergisi S.35, s.358-382.

Yavuz, Salih Sabri (2005). "Mirâc", Türkiye Diyanet Vakfi İslam Ansiklopedisi, İstanbul, 30. Cilt, s.132-135.

Yazır, Elmalı'lı Muhammed Hamdi (tarihsiz). Hak Dini Kur'an Dili, Eser Neşriyat, 5. Cilt, s. 3141-3145. 
